\title{
Wise Desire-Priorities: Hedonism or Moral Integrity?
}

\author{
Gunnar Salthe ${ }^{1} \&$ Nicolay Gausel ${ }^{1}$ \\ ${ }^{1}$ Faculty of Health and Social Sciences, Centre for Emotion Research, Østfold University College, Fredrikstad, \\ Norway \\ Correspondence: Nicolay Gausel, Faculty of Health and Social Sciences, Centre for Emotion Research, Østfold \\ University College, Fredrikstad, 1757 Halden, Norway. Tel: 47-6930-3198. E-mail: nicolay.gausel@hiof.no
}

\author{
Received: August 11, 2014 Accepted: August 25, 2014 Online Published: August 25, 2014 \\ doi:10.5539/res.v6n3p109 URL: http://dx.doi.org/10.5539/res.v6n3p109
}

\begin{abstract}
Although there are several philosophical theories about what constitutes 'good life', few focuses on which type of desires pay off for those who entertain them. We therefore investigate empirically how people prioritize among desires through a global assessment of what lives they most want to live. In the current study $(\mathrm{N}=154)$, we presented them with 26 questions about the type of life they could find desirable. Structural Equation Modeling revealed systematic differences in how a hedonistic attitude and an attitude of moral integrity differently predicted desires towards life. And as older participants tended to be less supportive of hedonistic attitudes, our results argue against hedonism.
\end{abstract}

Keywords: quality of life, global desires, hedonism, eudaimonia, moral integrity

\section{Introduction}

Aristotle (trans. 1985) argued that happiness meant successful goal-attainment where the best life (i.e., eudaimonia) is the life where we exercise and develop our capacities to fulfill the requirements of the virtues, being indifferent of other desires (see also, Annas, 1993; Nussbaum, 1994). In stark contrast, modern theories in the utilitarian tradition argues that fulfillment of all desires (i.e., everything that matters to a person, normatively, as this person sees it) contributes to a good life-including hedonistic desires (Sidgwick, 1874/1982; Griffin, 1986/1990; Parfit, 1984/1991). The inclusion of all desires postpones an answer to the practical question: Which desires is it egoistically rational to entertain? Griffin includes a speculative answer to this question in his theory of what well-being is (Griffin, 1986/1990); but we think the issue of choosing the best desire-priority may be addressed empirically while still paying respect to the philosophical arguments.

The current study thus presented people with a set of desires that empirical research has shown to be of importance for participants' well-being. Using Structural Equation Modeling, we provide empirical support for two different attitudinal desire-priority profiles that vary with age among our participants. Since accumulated age may cause accumulated life experience, we assume a tendency to choose wiser sets of desires with increased age. On this assumption, eudaimonia theory (Aristotle, trans. 1985) will be incorrect if we find that older people are just as interested in hedonistic desires as younger people. If eudaimonia theory survives this test, then people who abandon a purely hedonistic attitude towards life might be better off.

\subsection{Aristotle's Anti- hedonism}

While the modern utilitarian traditions acknowledges all desires, Aristotle holds that only satisfaction of those motivated by the virtues will contribute to a good life. There are two reasons for Aristotle's recommendation: First, virtues (e.g., temperance, fairness, courage) are standards of conduct; all they require is that our acts represent the standards we hold. They are thus activities that still are ends in themselves. If practicing these standards is everything we require, nothing beyond our own control can stop us from being altogether satisfied. Secondly, the virtues advocated by Aristotle are such that they allow human beings to exercise and fully develop their capacities as rational, active, social and emotional creatures (Aristotle, trans. 1985).

That said, it is not easy to become altogether virtuous. It is, for example, hard to prefer courageous behavior before continued existence, or to prefer justice before self-interest. And we often behave irrationally when we are confronted with hedonistic desire-fulfillment; we sometimes fail when we would be better off by postponing immediate pleasures, or we avoid dangers or find it difficult to endure some contemporary pain in order to gain positive pay-offs in the future. Most people have mixed motivations. Realizing that our lives are finite, we might 
think that up until now we have wasted our time (Rogers, 1961). Ironically, we then sometimes respond by even more hedonism, or suppress the thought of mortality rather than facing it, as Aristotle recommends (Annas, 1993; Nussbaum, 1993, see also Rogers, 1961).

Aristotle (trans. 1985) therefore admitted that in order to act morally most people need self-control and guidance that is provided not only by their subjective sense of shame (see also, Gausel \& Leach, 2011), but also by socially imposed rules, standards and obligations. In a modern western society, people are likely to hold moral values like; benevolence, respect for the autonomy of others, respect for others' rights, and civil courage (even though they sometimes fail to respect these values). In support of this, a German study by Greitemeyer, Fischer, Kastenmüller and Frey (2006) showed that acts of civil courage were partly motivated by felt obligations to practice social norms, while acts of benevolence were motivated by seeing another person as dependent on their help.

An obvious question arises, however: How satisfied will we be if we endorse Aristotle's view but fail practicing the virtues? In contrast to Aristotle's recommendations, many of our desires are directed towards external objects such as material wealth and honor. Success in achieving these aims is partly beyond our control, though; with such ends, satisfaction with life depends on luck (Aristotle, trans. 1985). Because of this, Aristotle suggests we should not desire them. Still, it is tempting to ask: Why should not fulfillment of hedonistic desires and desires for acknowledgement contribute to increased well-being when people in fact entertain such desires? Although happy partly by luck, they still feel happy. And honestly enough, Aristotle (trans. 1985) admits that those who direct their attention towards external, hedonistic desires will be satisfied when these ends are achieved - as would those who want to be virtuous come to judge their lives as a success if they in fact practice the virtues. Hence, it seems that a good life may relate to both virtuous desires and hedonistic desires.

\subsection{The Modern Utilitarian Tradition}

The utilitarian tradition started off with Bentham and Mill. They argued that human motivation is fundamentally hedonistic (Bentham, 1823/1907; Mill, 1861/1991). Modifying this view, modern utilitarians hold that it is the fulfillment of all desires that produces a good life, not simply pleasure along with avoidance of pain (Sidgwick, 1874/1982; Griffin, 1986/1990; Parfit, 1984/1991). There is some empirical support for the modern view: When people are asked about how happy they think they are, then their answers tend to differ from their answers to questions about how satisfied they are. For example, elderly people report being more satisfied than young people; in return, young people are happier than elderly (Hellevik, 2008). It can be argued that this pattern may be caused by a decline in ambitions - that old people are satisfied with less. Still, the results indicate that people are able to distinguish between satisfaction of desires for pleasurable experiences (hedonistic desires) and satisfaction of all desires.

Rejection of desires directed towards other objects than pleasure (non-hedonistic desires) seems unreasonable as we would then deprive ourselves of the happiness caused by fulfillment of these desires. Consequently, our well-being would probably drop (Sidgwick, 1874/1982). In support of this, Diener and Fujita (1995) found that among 21 resources that contributed to life satisfaction, five of them contributed to life satisfaction without producing any hedonistic gain. And the more relevant a resource was for each person's goals, the more that resource tended to correlate positively with subjective well-being.

Unlike Aristotle's view and those of the early utilitarians, a pure desire-fulfillment theory is neutral to the issue of which desires pay best off. We may therefore use this theory to pose our empirical question. If what a good life is for a person depends on that person's desires, it might be possible to compare the amount of desires-fulfillment between people depending on their desire-priorities - that is, if this theory allows for comparisons.

As desires are directed towards a variety of objects, Rawls (1971/1991) holds that we cannot compare degrees of desire-fulfillment across all sorts of desires. The best we can do, according to Rawls, is to work out our own conception of "a good life" by organizing our lives. That is, to co-ordinate and plan ahead our actions to have many important, though divergent, desires satisfied. He therefore argues that one should take into account what we know about our future, revise or drop plans as our values change, and fill in the details as we learn more about future options.

\subsection{Global Assessment: Griffin's Departure from a Formal Definition of 'Good-Life'}

On the Rawlsian conception, the dynamic plan of life marks the limit of prudential reasoning. If this is correct, we cannot know which set of desires to recommend as best.

Griffin (1986/1990) disagrees. He holds that well-being is satisfaction of actual informed desires, and he 
suggests that since Rawlsian (1971/1991) plans of life are "packages" of desire-fulfillment, we may rank them in order to find the highest ranked life. By adopting this global assessment procedure, we avoid Rawls' incommensurability problem.

Sheldon and Niemiec (2006) found, throughout four studies, that when people endorsed their actions, felt competent and felt connected to close others, each asset contributed to subjective well-being - but a balance between them contributed over and above the total amount. The balance is a property of the plan, the desire-fulfillment package. The balance-effect thus also speaks in favor of global assessment.

Griffin (1986/1990) is, however, not quite neutral to the issue of the prudentially recommended set of desires. He argues that for a desire to be informed we must appreciate the true nature of its object. This requires some life experience since it is often only after we have satisfied a desire that we fully learn how attainment of its object affects us; whether it really did us any good. He then argues that among our desires, there are, for him, only five types directed towards objects that we feel really make our lives worth living; accomplishments, a decent life, pleasurable experiences, close personal relationships and knowledge. He holds that a decent life consists of liberty, psychological capacity for autonomous decisions, and a minimum of material resources. Griffin's (1991) main point is that there is such a potential list of important types of objects; although he is less certain about how to categorize them. For example, what Griffin terms "accomplishments" might as well be termed "involvements". The point is, that we are involved with actions directed towards objectives we find important regardless of what others might think of them. A list such as that of Griffin can therefore aid us in forming global desires (plans of life) because it informs us what good packages of desire-fulfillment should contain.

We have then two theoretical answers to the issue of which set of desires to recommend for prudential reasons: Aristotle's eudaimonia-view which exclude hedonistic desires and Griffin's list which includes them. Note that neither of these two recommends a purely hedonistic set of desires. We want to address this issue empirically.

\subsection{Well-being: A Proposed Set of Six Desires}

How can we recommend a certain set of desires that would increase well-being? For us, the answer is an empirical one. Inspired by Griffin's (1986/1990) argument for the possibility of ranking global desires (plans of life), we have designed a list of six different desire-priorities that should be familiar to people at large and their concept of a "good-life"; but we think we should allow each individual to rank their desires based on their individual choices regardless of what we think the ranking of desires should be. Based on findings from the empirical well-being literature, we therefore suggest a list slightly different from that of Griffin, a list of two types of family relations (i.e., keeping personal relations to parents and siblings, or having children and a spouse), passive pleasures, meaningful involvements, autonomy, and religious duties.

\subsubsection{Pleasurable "Passive" Experiences}

Contrary to the recommendations of Aristotle (trans. 1985), it is obvious that people do appreciate even passive pleasurable experiences. Empirical research on happiness or well-being seems to accept this as they have observed systematic differences in how people prioritize among passive pleasures-especially those associated with the consumer industry (for a discussion, see Dittmar, 2008). Even though people typically appreciate these pleasures and knit them to their subjective well-being, they have been shown to be associated with less life satisfaction (Dittmar, 2008). Despite this, people still believe that passive pleasures such as "having a good time" or to be "good-looking" are associated with happiness and well-being. Therefore, pleasurable "passive" experiences should be measured as a desire-priority in its own right.

\subsubsection{Autonomy}

Self-determination theory defines autonomy as self-endorsed actions, distinguished from a desire for independence (Chirkov, Ryan, Kim, \& Kaplan, 2003). This accords somewhat with the view that autonomy is a capacity for working out what it seems best to do, combined with the ability to choose accordingly in spite of possible conflicting motivation (Dworkin, 1988; Mele, 1995; Salthe, 2003). Since autonomy consists of acting in accordance with the agent's values, we expect that, insofar as people do so, autonomy should be associated with a good life. In support of this, Chirkov, Ryan, Kim and Kaplan (2003) found that autonomy contributed to well-being across four different cultural contexts-in the United States, Russia, Korea, and Turkey. This indicates that autonomy is a universal desire and should therefore be measured as a possible desire-priority.

\subsubsection{Meaningful Involvement}

Concerning engagement in leisure activities, Pelletier, Vallerand, Green-Demers, Brière and Blais (1995) found that such engagement contributed to well-being if the motivation for participating in them was self-determined, and depending on the degree of such motivation. This suggests that engagements in activities contribute to 
well-being if desired. This conclusion is supported by the findings of Diener and Fujita (1995). They found that personal resources contributed more to well-being if they matched each person's goals or personal strivings. Moreover, in an Australian study (Omodei \& Wearing, 1990), involvement measured as flow experience (being absorbed in an activity) correlated strongly with having created something that had a sense of purpose and meaning, labelled need satisfaction (see also, Ruehlman \& Wolchik, 1988). Hence, meaningful involvement should also be measured as a desire-priority.

\subsubsection{Contact with One's Original Family}

Personal attachments are important for humans (for a discussion, see Baumeister \& Leary, 1995), but people may have different understandings in regard to who is most important to them. For example, when undergraduate students were asked to rate the three most importance persons in their lives, their parents dominated-before spouse, boyfriend or girlfriend (Ruehlman \& Wolchik, 1988). In the same vein, Rodriguez, Mira, Myers, Morris and Cardoza (2003) found that support from their respondets'original family enhanced well-being. Hence, the desire to have contact with one's own, original family should also be measured as a desire-priority that contributes to well-being.

\subsubsection{Creating One's Own Family}

To form a family on one's own is a widely accepted desire that people hold as important for their self-image and their life-development (Erikson, 1985). Not surprisingly, people that are in a stable relationship report that it provides them with increased well-being. For example, Levitt, Weber and Clark (1986) found that for mothers of infants, support from their spouse was the strongest contributor for the mother's well-being (even stronger than the support they received from their mothers). And in a careful review, Myers (2000) reported that married people seem to be to be happier than unmarried, but that the effect naturally depended on the quality of the marriage. Acknowledging the importance of forming a family (Erikson, 1985), this desire-priority would need to be measured as it clearly relates to well-being.

\subsubsection{Religiosity}

There is increasing support that fulfillment of religious ambitions might contribute to well-being - that is, to the extent that people hold such standards. For example, in a recent study, Jackson and Bergeman (2011) found that from midlife (but especially in older age) the effect of religious practices and spirituality on well-being was mediated and even enhanced by perceived control. They suggested that religious beliefs aid people in retaining their level of well-being despite increased difficulties typical for older age. In a worldwide study, Denier, Tay, and Myers (2011) found that religious beliefs somewhat promote subjective well-being, but that it was mediated with social support, respect and a sense of meaning in life. Dy-Liacco, Piedmont, Murray-Swank, Rodgerson, and Sherman (2009) found that among Filipinos religious faith enhanced pro-sociality, the experience of purpose in life and a feeling of self-actualization. Moreover, it reduced negative affect even when the effect of psychological functioning was controlled for (see also, Wink \& Dillon, 2003). Thus, we should measure the religiosity as a desire-priority as it contributes to well-being (at least for those who embrace it).

\section{The Current Study}

Unlike Aristotle (trans. 1985), the modern utilitarian tradition do not hold that what is morally good merge with what it is egoistically rational to do (Sidgwick, 1874/1982; Griffin, 1986/1990; Parfit, 1984/1991). Kant goes even further: He holds that due to our capacity for autonomy, people typically stand on a cross-road. They can either satisfy natural dispositions - typically hedonistic - or they can act as they find morally correct - typically virtuous (Kant, 1786/1991). We cannot then assume the Aristotelian view. Rather, we expect that global desire-profiles will vary mainly depending on an attitudinal orientation towards involvement with virtuous values (i.e., a moral attitude) or an attitudinal orientation towards involvement with self-interested hedonistic values (i.e., a hedonistic attitude).

Even though we expect general support for the different desires (except from religiosity, as some view this as important for a good life while others view it as detrimental), we expect that people who tend to support a hedonistic attitude towards life will be more inclined towards passive pleasures and less inclined to seek fulfillment of eudaemonistic desires (i.e., meaningful involvement, religiosity, autonomy). In contrast, those who tend to support a more moral attitude towards life will be more inclined to embrace meaningful involvements, autonomy, and religiosity; they will be less inclined to seek passive pleasures.

We expect that the general attitudes towards life change with increased life experience, that people tend to achieve some insight into what is most satisfying as they grow older (or less satisfying). In some accordance with eudaimonia theory, we therefore expect that people will typically tend to turn away from a purely hedonistic 
attitude towards life as they accumulate life experience. Younger participants should therefore be more supportive of a hedonistic attitude than older participants. For the attitude of moral integrity we expect a different pattern. As moral development is sufficiently developed at the age of majority (Kohlberg, 1973), it is less obvious that age will predict increased morality. Thus, as morality should be fully developed at the age of adulthood (all of our participants were older than 18 years) we expect no differences in age regarding support of a moral attitude.

\section{Method}

\subsection{Participants}

The study included 154 Norwegian undergraduate participants (36 men and 118 women; mean age: 27.8, age range: 18-51 years) that voluntarily agreed to partake in a questionnaire study focusing on well-being.

\subsection{Procedure}

The questionnaires were collected during lectures and participants were informed that participation was voluntary and that they were guaranteed full anonymity. The questionnaires were collected as the participants left.

On the first page of the questionnaire, participants were asked to fill in their demographics. This was followed by a second page where we presented the participants for our list of presumably important desires. The desires were introduced as a list of lives one could dream of living. For each item, they were asked to mark whether they would want it like this on a scale ranging from 1 (not at all) to 7 (complete agreement).

\subsection{Measures}

\subsubsection{Attitudes towards Life: Hedonism}

We measured Hedonism as a latent factor using two manifest variables as its indicators: Social Hedonism ( $\alpha$ $=.74$ ) was measured with four items: "I want to have fun", "I want it comfortable", "I want to be liked by everyone" and "I want many friends and acquaintances" and Short-time Hedonism $(r=.28)$ was measured with two items: "I want to eat and drink well" and "I want to make few plans. I take what comes as it comes".

\subsubsection{Attitudes towards Life: Moral Integrity}

Moral Integrity was measured as a latent factor with two manifest indicators: Anti-paternalistic Benevolence ( $r$ $=.26$ ) was measured with two items: "I want to use time and money on helping others" and "I want to let people live as they want to, as long as they are no trouble to others." Civil Courage $(r=.30)$ was measured with two items: "I want to be courageous" and "I want to speak up for what I hold to be important".

\subsubsection{Important Desires}

Autonomy ( $\alpha=.71)$ was measured using three items: "I want to be preoccupied with many activities", "I want to decide my activities myself, without interference from anyone" and "I want my days consisting of activities I like". Meaningful Involvement $(\alpha=.76)$ was measured using four items: "I want to accomplish something I find important", "I want surplus energy and a go-ahead spirit", "I want to learn more about what interests me" and "I want it nice around me". Passive Pleasures $(\alpha=.66)$ was measured with three items: "I want much spare-time", "I want to be good-looking" and "I want to relax and have a good time". Contact with one's Original Family ( $r$ $=.49$ ) was measured using two items: "I want to socialize much with my parents" and "I want to socialize much with my siblings." Creating one's Own Family $(\alpha=.68)$ was measured using three items: "I want a lover", "I want to be married" and "I want children". Religiosity was measured with a single item: "I want to live as God wants me to".

\section{Results}

\subsection{Descriptive Statistics}

As seen in Table 1, even though a hedonistic attitude to life and an attitude of moral integrity were weakly correlated $(r=.33, p<.05)$, they were both highly embraced by our participants. Interestingly, participants rated the attitude of moral integrity as more important to them than the attitude of hedonism. In fact, a $t$-test, revealed that this difference was significant, $t(153)=6.35, p<.001$ (Cohen's $d=.58$ ). 
Table 1. Scale inter-correlations and descriptive statistics

\begin{tabular}{|c|c|c|c|c|c|c|c|c|c|c|c|c|c|}
\hline & Variable & 1 & 2 & 3 & 4 & 5 & 6 & 7 & 8 & 9 & 10 & 11 & 12 \\
\hline 1 & Attitude: Hedonism & - & & & & & & & & & & & \\
\hline 2 & Attitude: Moral integrity & $.33^{*}$ & - & & & & & & & & & & \\
\hline 3 & Social hedonism & $.78^{*}$ & $.32 *$ & - & & & & & & & & & \\
\hline 4 & Short-time hedonism & $.88^{*}$ & $.25^{*}$ & $.38^{*}$ & - & & & & & & & & \\
\hline 5 & Civil courage & $.37 *$ & $.77 *$ & $.35^{*}$ & $.28 *$ & - & & & & & & & \\
\hline 6 & Anti-paternalistic benevolence & $.19 *$ & $.85^{*}$ & $.18^{*}$ & .14 & $.31 *$ & - & & & & & & \\
\hline 7 & Passive pleasures & $.54 *$ & $.21 *$ & $.56^{*}$ & $.37 *$ & $.27^{*}$ & .09 & - & & & & & \\
\hline 8 & Contact with original family & $.17^{*}$ & .16 & $.30^{*}$ & .03 & .15 & .11 & $.21^{*}$ & - & & & & \\
\hline 9 & Create one's own family & $.18^{*}$ & .12 & $.19^{*}$ & .11 & $.17^{*}$ & .04 & $.17 *$ & $.20^{*}$ & - & & & \\
\hline 10 & Autonomous activity & $.45^{*}$ & $.38 *$ & $.45^{*}$ & $.31 *$ & $.39 *$ & $.25^{*}$ & $.25 *$ & .09 & .09 & - & & \\
\hline 11 & Meaningful involvement & $.18^{*}$ & $.34 *$ & $.28^{*}$ & .06 & $.36^{*}$ & $.20^{*}$ & $.17^{*}$ & .08 & .13 & $.31^{*}$ & - & \\
\hline 12 & Religiosity & .12 & $.26^{*}$ & .12 & .09 & $.20^{*}$ & $.23 *$ & .15 & .04 & .05 & .10 & .09 & - \\
\hline $\mathrm{Me}$ & $\operatorname{an}$ & 5.33 & 5.78 & 5.93 & 4.72 & 6.07 & 5.50 & 5.38 & 4.76 & 5.75 & 5.39 & 6.29 & 2.54 \\
\hline SD & & 0.82 & 0.73 & 0.85 & 1.12 & 0.81 & 0.99 & 1.06 & 1.38 & 1.21 & 0.95 & 0.66 & 1.68 \\
\hline$\alpha / \mathrm{r}$ & & - & - & .74 & .28 & .30 & .26 & .66 & .49 & .68 & .71 & .76 & - \\
\hline
\end{tabular}

As the six presumably important desires had only low inter-correlations (ranging from .04 to .39) we were assured that the participants were able to differentiate among the presented desires and therefore could rank these independently. In fact, among the desires, meaningful activity was ranked highest, with the desire to create one's own family as the second most important desire. The third most important desire was the desire to engage in autonomous activity. This was closely followed by the desire to seek passive pleasures. On fifth place, was the desire to stay in contact with one's original family, and as expected, the desire of religiosity was the least important desire-although as indicated by the large standard deviation, there was rather large disagreement among participants on its importance.

\subsection{Explaining the Relationship between Age, Attitudes and Desires}

With the help of AMOS 20, we used Structural Equation Modeling (SEM) to examine our hypothesized relationships between age, our two latent factors of "hedonism" and "moral integrity", and our six desires. As this model fit the data very well, $\chi^{2}(21)=29.80, p=.096, \chi^{2} / d f=1.42, I F I=.972, C F I=.967, R M S E A=.052$, we could rest assured that our hypothesized model was a reliable representation of participants' attitudes and desires. 


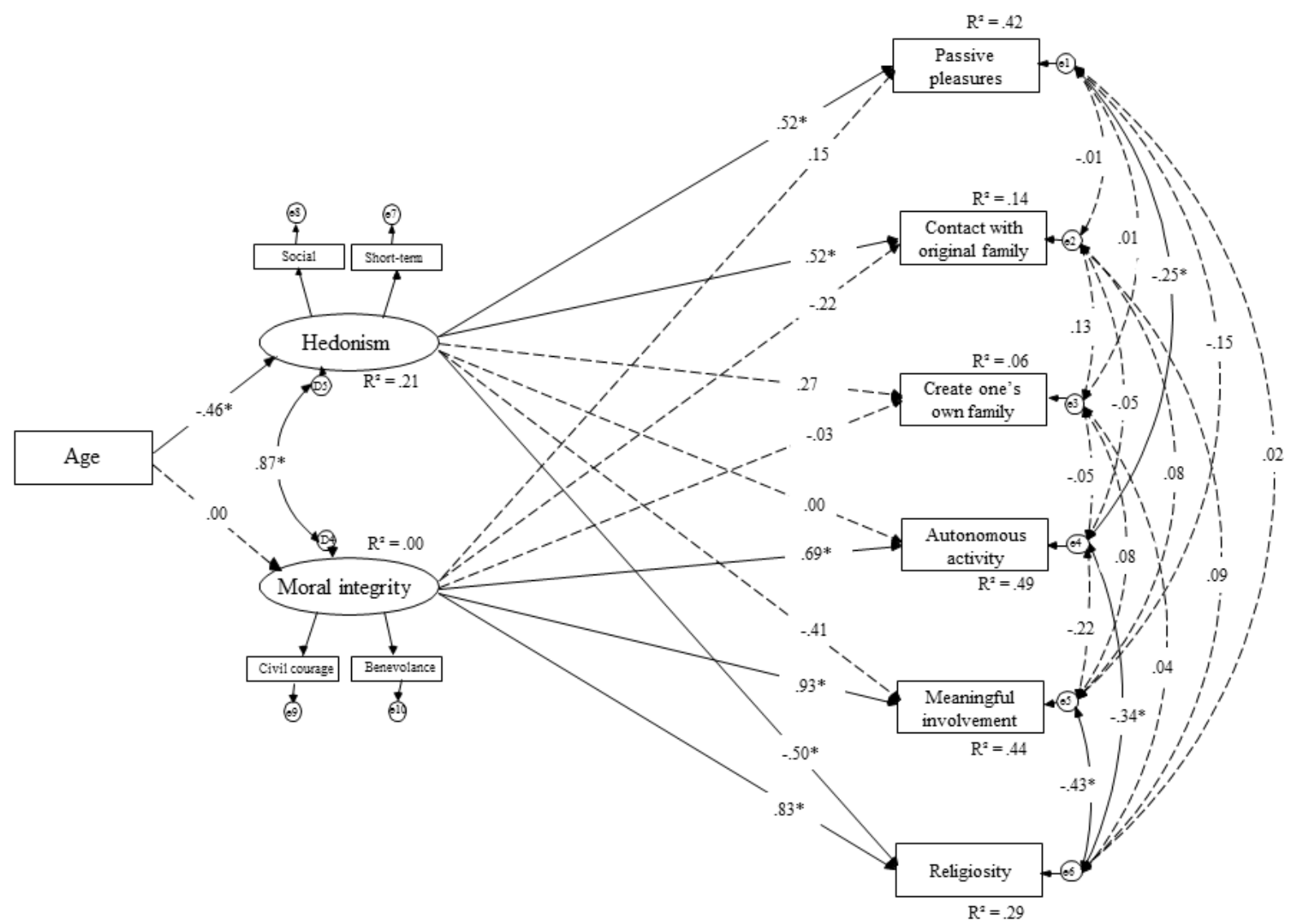

Figure 1. Structural Model of age predicting attitudes, and attitudes predicting desires

Note. Dashed lines indicate non-significant relationships and solid lines indicate significant relationships where * $=p<.05$

As seen in Figure 1, our hypothesis that both older and younger age should endorse an attitude of moral integrity was supported. Moreover, just as we had hypothesized, older age was a reliable negative predictor of a hedonistic attitude to life and younger age was a positive predictor of a hedonistic attitude (explaining as much as $21 \%$ of its variance).

Moreover, just as expected, the more our participants endorsed an attitude of hedonism, the more they expressed a desire for passive pleasures. In fact, this attitude of hedonism explained as much as $42 \%$ of the variance for passive pleasures. Also as expected, the more our participants endorsed an attitude of hedonism the less they expressed a desire for religiosity (explaining $29 \%$ of its variance). And as expected, an attitude of hedonism was unrelated to both the desire for a meaningful involvement and for autonomous activity. It was also unrelated with the desire of creating one's own family (explaining only $6 \%$ of its variance). However, and contrary to our expectations, the more our participants endorsed an attitude of hedonism the more they expressed a desire to maintain contact with one's original family (explaining $14 \%$ of its variance).

In contrast, perfectly supporting our hypotheses, the more our participants endorsed an attitude of moral integrity, the more they expressed a desire to fulfill religious duties. Moreover, the more they endorsed an attitude of moral integrity, the more they expressed a desire to engage in meaningful involvement (explaining as much as $44 \%$ of its variance) and the more they expressed a desire to engage in autonomous activity (explaining as much as $49 \%$ of its variance). Just as expected, an endorsement of an attitude of moral integrity was unrelated with the desire to engage in passive pleasures, with creating one's own family, and with the desire to maintain contact with one's original family.

\section{Discussion}

Even though there are several theories debating 'good life', we favored the desire-fulfillment theory as our tool in the exploration of which desires people actually prioritize. As we think that the issue of choosing the best set 
of desires can be addressed through the experience gathered by age we allowed our participants to express their attitudes to life and then rank, as suggested by Griffin (1986/1990), the desires that they think will make their life good. Hence, our contribution to the 'good life' debate is an empirical one.

\subsection{Attitudes towards Life}

Some participants entertain a hedonistic attitude focusing on social and short-time hedonism; others embrace an attitude of moral integrity focusing on civil courage and anti-paternalistic benevolence. Not surprisingly, our participants endorsed both attitudes but to a slightly different extent. As social life requires that people behave morally (Gausel \& Leach, 2011) moral objectives should be pursued somewhat further than what gains the agent (Parfit, 1984/1991). This argument was highlighted by our findings. The participants clearly supported an attitude of moral integrity. In fact, they reported to be significantly more interested in this, than in a hedonistic attitude. That said, we did not find support for an Aristotelian eudaimonistic attitude towards life. Regarding morality, our results might cohere better with a modern, Kantian conception than with the Aristotelian one (Aristotle, trans. 1985; Kant, 1786/1991, 1983/1991). Moreover, for our participants, contrary to both these philosophers, a moral attitude did not exclude a hedonistic one; rather, the two attitudes were positively correlated. Hence, our participants expressed a nuanced approach to life where moral integrity was ranked as the most important attitude to life without rejecting short-time and social hedonism.

\subsection{Age and Attitudes to Life}

As eudaimonistic theory recommend certain aims as universally good for human beings (Annas, 1993; Nussbaum, 1993), people are advised to direct their efforts towards these ends while remaining indifferent towards much of what people normally would find valuable (Nussbaum, 1994). If this is true, we should expect that accumulated life experience (or increased age) would be negatively predictive of a hedonistic attitude to life and positively predictive of an attitude of moral integrity, reflecting Aristotle's view.

However, Aristotle's view was only partly supported; it is true that increased age was negatively predictive of a hedonistic attitude, but we did not find support for Aristotle's view that older age would be more predictive of an attitude of moral integrity, than young age. This result might be explained by the fact that moral matters form an important part of modern education and upbringing. There is therefore no reason to expect that modern moral values are less supported by the younger people than by the middle-aged. When we compared the two general attitudes towards life, we found that people are generally more morally than hedonistically motivated, and this does not seem to change as people grow older. To some extent, this supports Ruch, Harzer, Proyer, Park and Peterson (2010) finding of a significant negative correlation between age and hedonism while priority on involvements and a (eudaimonistic) life of meaning were not correlated with age.

\subsection{The List of Important Desires}

Our participants endorsed five out of the six desires. They most favored meaningful involvement (or Griffin's accomplishment). Another desire that was highly ranked was the desire to form one's own family. By such, our results confirm Erikson's (1985) argument that forming a family is among the most important desires and it confirms Griffin's idea of the importance of close personal relations.

Directly after this came passive pleasures and autonomous activity. Even though the desire to engage in passive pleasures oppose the view of Aristotle, people do in fact endorse these - as admitted by both Griffin's and Sidgewick's approach. This finding is not surprising, because the western world and its consumer industry often promote passive pleasures as desirable, and in fact, as key to happiness (e.g., Dittmar, 2008).

Autonomous activity was also ranked highly, confirming the view that autonomy is important for a good life (e.g., Chirkov et al., 2003), especially as autonomy is the ability to decide to act in accordance with what the agent sees as the best thing to do (e.g., Dworkin, 1988).

The desire to stay in contact with one's original family was also endorsed, although this was ranked somewhat lower. Nevertheless, participants expressed that this desire was important for them. Hence, Griffin's idea that personal relations are important was indeed confirmed. These took the form of family relationships; relations to friends were associated with the general hedonistic attitude. Ranked lowest of all, was the desire of religiosity. Even though religiosity is a form of meaningful involvement, the large standard deviation exposed that our participants disagreed about its importance, indicating that this is more of an either-else desire. Either you decide to give away control to God, or you don't. Whatever the decision, religiosity still appears to be a potentially important desire.

Taken together, this list of desires is closer to that of Griffin than it is to that of Aristotle. The reason might be that Aristotle is partly wrong, or that our participants fail to be fully informed about the desires that they rank. 
Nevertheless, our results do demonstrate that people tend to support Griffin-type desires based on their experience with life, and they are therefore capable of differentiating among categories of desires, somewhat similar to those on Griffin's list.

\subsection{Attitude of Hedonism Predicting Desires}

We had hypothesized that we could trace systematic differences in how the two attitudes of hedonism and moral integrity would predict the desires on the list.

In line with this, an attitude of hedonism was a moderate, positive predictor of passive pleasures. However, and this might be problematic for the utilitarian tradition, an attitude of hedonism was negatively unrelated to meaningful involvement and unrelated to autonomous activity. One would expect the opposite if Bentham (1823/1907) and Mill (1861/1991) were right that human motivation is fundamentally hedonistic - i.e., that the more one embrace a hedonistic attitude, the more one would like to make autonomous decisions and do whatever we decide to do without other people interfering in these decisions. Normative hedonists may respond, however, that our participants are not philosophers who reflect over how they can pursue pleasurable goals in the long run. In other words, when our participants express a hedonistic attitude (i.e., to socialize with friends and feel pleasurable here and now), they express an attitude which is passive with a rather low level of self-discipline. If one should have long-term pleasurable satisfaction through autonomous activity and meaningful involvement one must be exertive and responsible, and this simply does not fit with this short-time 'here and now' hedonistic attitude that often go hand in hand with young age.

That said, there is still some autonomous tendency within the hedonistic attitude. As expected, hedonism did not fit well with religiosity. Thus, a hedonistic attitude was a significant moderate negative predictor of handing control over one's own life to God. Religiosity is simply not an option if one has an attitude of 'here and now' hedonism. Note again, that this supports Ruch et al. (2010) finding that that religious engagements correlate positively with a meaningful, eudaimonistic life but negatively with hedonism.

Perhaps surprisingly, hedonism was also a moderate, positive predictor of staying in contact with one's original family. As most people know, staying in contact with one's original family is not a case of seeking pleasure and avoiding pain. On the contrary, with family also come family-rules, obligations and responsibilities that are not about satisfying hedonistic pleasures. And often, family-relations can be emotionally and socially problematic (e.g., Erikson, 1985). Hence, this result argues against the early utilitarian tradition (e.g. Bentham,1823/1907; Mill, 1861/1991), but support the view of Sidgwick (1874/1982) that life is about the pleasure found in desire-fulfillment-as family-relations satisfies the need to belong (Baumeister \& Leary, 1995) regardless of whether the relationship is problematic or not (Gausel, 2013). In our sample, the hedonistic attitude may predict a desire to keep in contact with parents and siblings because our participants were above the age where their parents can command them and had typically not yet reached the age where their parents and siblings might need much help. The satisfying aspects of family relationships may then be fulfilled without challenging a hedonistic attitude.

\subsection{Attitude of Moral Integrity Predicting Desires}

As expected, the attitude of moral integrity represented the opposite predictive pattern of hedonism. There were no significant associations between an attitude of moral integrity and passive pleasures. This reflects the view of Aristotle that the more morally oriented one is towards life, the less interest there is for satisfaction of passive pleasures. Somewhat surprisingly, moral integrity was unrelated with the desire of having contact with one's original family and with forming a family of one's own.

In support of Kant, an attitude of moral integrity was a strong and positive predictor of the desire to engage in autonomous activity. Naturally, there must be some level of civil courage in order to stand up for one's own decisions, and through this, be able to lead an autonomous life (see also Chorkin et al., 2003). Supporting Aristotle, moral integrity was also a strong, positive predictor of meaningful involvement. This finding lends support to Pelletier's and colleagues' (1995) arguments that self-determined involvement in activities contribute to well-being (see also, Diener \& Fujita, 1995); we may add, in particular for those who embrace moral integrity.

Finally, an attitude of moral integrity was a strong, positive predictor of religiosity. This makes sense if we see religiosity as a meaningful involvement. In our data, this involvement does not merge with other forms of accomplishments because our respondents disagreed about the importance of religion. Some would perhaps argue that religiosity is not an act of autonomy as long as autonomous activity is unrelated with religiosity in the bivariate correlations, and even negatively correlated with it in the SEM-model. In response to this, it is important to note that the measurement of autonomous activity in this study is focused on deciding one's own 
activities and not on responsibility and agency in general. We should admit that religiosity is about a decision to give away control - that is, to let God decide how one should live; it is a decision just as autonomous as deciding not to live as God wants. Therefore, for those who embrace the desire of religiosity, living the way that God wants is part of what it means for them to live a good life (see; Denier et al., 2011; Jackson \& Bergeman, 2011; Wink \& Dillon, 2003).

\section{Possible Shortcomings}

Some possible short-comings should be mentioned. Admittedly, our study does not measure the faculty of judgment as part of a person' moral competence, essential to Aristotle's reasons for holding that moral development continues beyond the age of maturity (trans. 1985). Nor does the attitude of moral integrity truly reflect a virtuous attitude as in the Aristotelian sense. Nevertheless, time has changed since Aristotle's theory of eudaimonia was launched. Aristotle held that community life should be based on friendships which embraced the virtues (trans. 1985). This political theory was challenged when the Protestants succeeded in opposing the Catholic Church. As a reaction, liberal theory based on governmental respect for human rights gradually replaced Aristotelian communitarian conceptions (Kant, 1803/1991; Rawls, 1971/1991; Holmes, 1989). Basing our measurements of moral integrity on a liberal conception is therefore more valid in a modern society than a morality-measurement based on an Aristotelian conception. In a modern, liberal conception, however, morality is secured by laws and social institutions rather than by educating each person's character unto perfection. Our results are therefore not quite valid for testing Aristotle's views on moral development, but that is precisely what makes them valid for the lives of our participants.

It should also be noted that we used a conception of well-being based on real desire-fulfillment, a modified version of the view suggested by Griffin (1986/1991). This approach reduces the incommensurability problems to comparisons across the categories on the list. People may compare degrees of desire-fulfillment within each category because they then compare desire-fulfillments of similar nature. Comparison across categories is replaced by choices between entire plans of life (as desire-packages), and comparison of plans do not require more than ranking them (Griffin, 1986/1990). It is thus possible for each of our respondents to compare his or her success in implementing his or her plan as this plan changes. Although this means choosing for comparison one among several theories of happiness, our approach is less biased than it might seem to be. It allows for the Aristotelian claim that coherence among personal ends is necessary for full satisfaction (Annas, 1993). Moreover, ranking desire-fulfillment allows for hedonistic and non-hedonistic desires alike. Of course we do not know how our participants has formed and reformed their attitudes towards life and their priorities between desires. Nevertheless, Griffin's theory describes how comparison between their earlier and present lives is feasible, and this supports our assumption that increased age tends to improve life wisdom.

\section{Conclusion}

Our recommendations originate from an empirical approach. The advantage of looking for and addressing the empirical premises of normative conclusions is that empirical statements may be controlled against observation. Our Structural Equation Modeling revealed systematic differences in how a hedonistic attitude and an attitude of moral integrity predicted individual desire-priorities. We also observed that older participants tended to be less supportive of hedonistic attitudes, and we observed that age was not a predictor of an attitude of moral integrity. For those who most embraced an attitude of hedonism, a good life meant priority on passive pleasures. Those who stressed an attitude of moral integrity embraced a desire-package oriented towards meaningful involvements and autonomy; including religiosity as an important form of meaningful involvement. Enduring relations to others seems to be an important part of a good life for everyone, regardless of attitudes.

To the extent that increased age reflects increased life wisdom, we may recommend the desire-package embraced by those who adopted moral integrity, with enduring personal relations added. We admit that pleasurable experiences do contribute to a good life, but passive and immediate pleasures should not be our main objective; pleasures caused by involvements and lasting personal relationships might be more recommendable.

\section{References}

Annas, J. (1993). The Morality of Happiness. Oxford: Oxford University Press.

Aristotle (1985). The Nicomachean Ethics (Trans. by T. Irwin). Indianapolis: Hackett Publishing Company.

Baumeister, R. F., \& Leary, M. R. (1995). The need to belong: Desire for interpersonal attachments as a fundamental human motivation. Psychological Bulletin, 117, 497-529. http://dx.doi.org/10.1037/0033 $-2909.117 .3 .497$

Bentham, J. (1823/1907). An Introduction to the Principles of Morals and Legislation (2nd ed.). Retrieved from 
http://www.econlib.org/library/Bentham/bnthPML.html

Chirkov, V., Ryan, M. R., Kim, Y., \& Kaplan, U. (2003). Differentiating Autonomy from Individualism and Independence: A self-Determination Theory Perspective on Internalization of Cultural Orientations and Well-Being. Journal of Personality and Social Psychology, 84(1), 97-110. http://dx.doi.org/10.1037 /0022-3514.84.1.97

Denier, E., Tay, L., \& Myers, D. G. (2011). The Religious Paradox: If Religion Makes People Happy, Why Are So Many Dropping Out? Journal of Personality and Social Psychology. http://dx.doi.org/10.1037/a0024402

Diener, E., \& Fujita, F. (1995). Resources, Personal Strivings, and Subjective Well-being: A Nomothetic and Ideographic Approach. Journal of Personality and Social Psychology, 68(5), 926-935. http://dx.doi.org /10.1037/0022-3514.68.5.926

Dittmar, H. (2008). Consumer society, identity, and well-being: The search for the 'good life'and the 'body perfect'. European monographs in social psychology series. London, New York, NY: Psychology Press.

Dworkin, G. (1988). The Theory and Practice of Autonomy. Cambridge: Cambridge University Press.

Dy-Liacco, G. S., Piedmont, R. L., Murray-Swank, N. A., Rodgerson, T. E., \& Sherman, M. F. (2009). Spirituality and Religiosity as Cross-Cultural Aspects of Human Experience. Psychology of Religion and Spirituality, 1(1) 35-52. http://dx.doi.org/10.1037/a0014937

Erikson, E. H. (1985). The life cycle completed: A review. New York, NY, US: W W Norton \& Co.

Gausel, N. (2013). Self-reform or self-defense? Understanding how people cope with their moral failures by understanding how they appraise and feel about their moral failures. In M. Moshe, \& N. Corbu (Eds.), Walk of Shame (pp. 191-208). Hauppauge, NY, USA: Nova Publishers.

Gausel, N., \& Leach, C. W. (2011). Concern for self-image and social-image in the management of moral failure: Rethinking shame. European Journal of Social Psychology, 41, 468-478. http://dx.doi.org/10.1002/ejsp.803

Greitemeyer, T., Fischer, P. Kastemüller, A. \& Frey, D. (2006). Civil Courage and Helping Behavior: Differences and Similarities. European Psychologist, 11(2), 90-98. http://dx.doi.org/10.1027/1016-9040.11.2.90

Griffin, J. (1986/1990). Well-Being: Its Meaning, Measurement and Moral Importance. Oxford: Oxford University Press.

Griffin, J. (1991). Against the taste model. In J. Elster, \& J. E. Roemer (Ed.), Interpersonal Comparisons of Well-being (pp. 4-70). Oxford: Clarendon Press.

Hellevik, O. (2008). Jakten på den norske lykken[Searching for the Norwegian Happiness]. Oslo, Norway: Universitetsforlaget.

Holmes, S. (1989). The Permanent Structure of Antiliberal Thought. In N. Rosenblum (Ed.), Liberalism and the Moral Life (pp. 227-253). Cambridge, MA: Harvard University Press.

Jackson, R. B., \& Bergeman, C. S. (2001). How does Religiosity Enhance Well-Being? The Role of Perceived Control. Psychology of Religion and Spirituality, 3(2), 149-161. http://dx.doi.org/10.1037/a0021597

Kant, I. (1786/1991). Grundlegung der Metaphysik der Sitten [Groundwork of the Metaphysics of Morals]. Stuttgart, Germany: Phillip Reclam jun.

Kant, I. (1803/1991). The Metaphysics of Morals. Cambridge: Cambridge University Press.

Kohlberg, L. (1973). The Claim to Moral Adequacy of a Highest Stage of Moral Judgment. Journal of Philosophy, 70(18), 630-646. http://dx.doi.org/10.2307/2025030

La Guardia, J. G., Ryan, R. M., Couchman, C. E., \& Deci, E. L. (2000). Within-Person Variation in Security of Attachment: A Self-Determination Theory Perspective on Attachment, Need Fulfillment, and Well-Being. Journal of Personality and Social Psychology, 79(3), 367-384. http://dx.doi.org/10.1037//0022 $-3514.79 .3 .367$

Levitt, M. J., Weber, R. A., \& Clark, M. C. (1986). Social Network Relationships as Sources of Maternal Support and Well-Being. Developmental Psychology, 22(3), 310-316. http://dx.doi.org/10.1037/0012-1649.22.3.310

Love, K. M., \& Murdock, T. B. (2004). Attachment to Parents and Psychological Well-Being: An Examination of Young Adult College Students in Intact Families and Stepfamilies. Journal of Family Psychology, 18(4), 600-608. http://dx.doi.org/10.1037/0893-3200.18.4.600

Lyubomirsky, S., Sheldon, K. M., \& Schkade, D. (2005). Pursuing Happiness: The Architecture of Sustainable 
Change. Review of General Psychology, 9(2), 111-131. http://dx.doi.org/10.1037/1089-2680.9.2.111

Mele, A. R. (1995). Autonomous Agents. From Self-Control to Autonomy. Oxford: Oxford University Press.

Mill, J. S. (1861/1991). Utilitarianism. In H. B. Acton (Ed.), John Stuart Mill: Utilitarianism, Liberty, Representative Government (pp. 1-69). London: J. M. Dent \& Sons Ltd.

Myers, D. G. (2000). The Funds, Friends and Faith of Happy People. American Psychologist, 55(1), 56-67. http://dx.doi.org/10.1037//0003-066X.55.1.56

Nussbaum, M. C. (1993). Non-relative Virtues: An Aristotelian Approach. In M. C. Nussbaum, \& A. Sen (Eds.), The Quality of Life (pp. 242-270). Oxford: Clarendon Press.

Nussbaum, M. C. (1994). The Therapy of Desire. Theory and Practice of Hellenistic Ethics. Princeton, New Jersey: Princeton University Press.

Omodei, M. M., \& Wearing, A. J. (1990). Need Satisfaction and Involvement in Personal Projects: Towards an Integrative Model of Subjective Well-being. Journal of Personality and Social Psychology, 59(4), 762-769. http://dx.doi.org/10.1037/0022-3514.59.4.762

Parfit, D. (1984/1991). Reasons and Persons. Oxford: Clarendon Press.

Pelletier, L. G., Vallerand, R. J., Green-Demers, I., Bière, N. M., \& Blais, M. R. (1995). Loisirs et santé mentale : les relations entre la motivation pour la pratique des loisires et le bien-être psychologique [Spare-time Activities and Mental Health: The Relations between the Motivation for Practicing the Activity and the Psychological Well-being]. Revue canadienne des siences du comportement, 27(2), 140-156.

Rawls, J. (1971/1991). A Theory of Justice. Oxford: Oxford University Press.

Rodriguez, N., Mira, C. B., Myers, H. F., Morris, J. K., \& Cardoza, D. (2003). Family or Friends: Who Plays a Greater Supportive Role for Latino College Students? Cultural Diversity and Ethnic Minority Psychology, 9(3), 236-250. http://dx.doi.org/10.1037/1099-9809.9.3.236

Rogers, C. (1961). On becoming a person. Boston: Houghton Mifflin.

Ruch, W., Harzer, C., Proyer, R. T., Park, N., \& Peterson, C. (2010). Ways to Happiness in German-speaking Counties: The Adaption of the German Version of the Orientations to Happiness Questionnaire in Paper-pencil and Internet Samples. European Journal of Psychological Assessment, 26(3), 227-234. http://dx.doi.org/10.1027/1015-5759/a000030

Ruehlman, L. S., \& Wolchik, S. A. (1988). Personal Goals and Interpersonal Support and Hindrance as Factors in Psychological Distress and Well-Being. Journal of Personality and Social Psychology, 55(2), 293-301. http://dx.doi.org/10.1037/0022-3514.55.2.293

Salthe, G. (2003). Planning and Deciding for People with Mental Retardation. Oslo, Norway: Unipub AS.

Sheldon, K. M., \& Niemiec, C. P. (2006). It's Not Just the Amount That Counts: Balanced Need Satisfaction Also Affects Well-being. Journal of Personality and Social Psychology, 91(2), 331-341. http://dx.doi.org/10.1037 /0022-3514.91.2.331

Sidgwick, H. (1874/1982). The Method of Ethics (7th ed.). Indianapolis: Hackett Publishing Company.

Wink, P., \& Dillon, M. (2003). Religiousness, Spirituality, and Psychological Functioning in Late Adulthood: Findings from a Longitudinal Study. Psychology and Aging, 18(4), 916-924. http://dx.doi.org/10.1037/1941 $-1022 . S .1 .102$

\section{Copyrights}

Copyright for this article is retained by the author(s), with first publication rights granted to the journal.

This is an open-access article distributed under the terms and conditions of the Creative Commons Attribution license (http://creativecommons.org/licenses/by/3.0/). 